\title{
Epidermis as a Platform for Bacterial Transmission
}

\begin{abstract}
Fernando Baquero ${ }^{1,2 *}$, Claudia Saralegui ${ }^{1}$, Daniel Marcos-Mencía ${ }^{1}$, Luna Ballestero ${ }^{1}$, Sergio Vañó-Galván ${ }^{3}$, Óscar M. Moreno-Arrones ${ }^{3}$ and Rosa del Campo ${ }^{1,4,5 *}$

1 Servicio de Microbiología, Hospital Universitario Ramón y Cajal and Instituto Ramón y Cajal de Investigación Sanitaria (IRYCIS), Madrid, Spain, ${ }^{2}$ Network Center for Research in Epidemiology and Public Health (CIBERESP), Madrid, Spain, ${ }^{3}$ Servicio de Dermatología, Hospital Universitario Ramón y Cajal, and Instituto Ramón y Cajal de Investigación Sanitaria (IRYCIS), Universidad de Alcalá, Madrid, Spain, ${ }^{4}$ Department of Health Sciences, Universidad Alfonso X El Sabio, Madrid, Spain, ${ }^{5}$ Centro de Investigación en Red en Enfermedades Infecciosas (CIBER-EEII), Madrid, Spain
\end{abstract}

The epidermis constitutes a continuous external layer covering the body, offering protection against bacteria, the most abundant living organisms that come into contact with this barrier. The epidermis is heavily colonized by commensal bacterial organisms that help protect against pathogenic bacteria. The highly regulated and dynamic interaction between the epidermis and commensals involves the host's production of nutritional factors promoting bacterial growth together to chemical and immunological bacterial inhibitors. Signal trafficking ensures the system's homeostasis; conditions that favor colonization by pathogens frequently foster commensal growth, thereby increasing the bacterial population size and inducing the skin's antibacterial response, eliminating the pathogens and re-establishing the normal density of commensals. The microecological conditions of the epidermis favors Gram-positive organisms and are unsuitable for longterm Gram-negative colonization. However, the epidermis acts as the most important host-to-host transmission platform for bacteria, including those that colonize human mucous membranes. Bacteria are frequently shared by relatives, partners, and coworkers. The epidermal bacterial transmission platform of healthcare workers and visitors can contaminate hospitalized patients, eventually contributing to cross-infections. Epidermal transmission occurs mostly via the hands and particularly through fingers. The three-dimensional physical structure of the epidermis, particularly the fingertips, which have frictional ridges, multiplies the possibilities for bacterial adhesion and release. Research into the biology of bacterial transmission via the hands is still in its infancy; however, tribology, the science of interacting surfaces in relative motion, including friction, wear and lubrication, will certainly be an important part of it. Experiments on finger-tofinger transmission of microorganisms have shown significant interindividual differences in the ability to transmit microorganisms, presumably due to genetics, age, sex, and the gland density, which determines the physical, chemical, adhesive, nutritional, and immunological status of the epidermal surface. These studies are needed to optimize interventions and strategies for preventing the hand transmission of microorganisms.

Keywords: epidermis microbiota, bacterial transmission, protection pathogens, heterogeneity transmitters, skin tribology 


\section{INTRODUCTION}

The transmission of infectious microorganisms between individuals through skin contact has long been known, driving the development of hygiene because of the impracticality of perpetual skin sterilization. Our knowledge of the skin microbiota has increased considerably since the introduction of massive sequencing techniques, particularly for bacteria and fungi, demonstrating the existence of specific ecosystems in differentiated areas. As with other colonized body surfaces, the detailed composition of a healthy microbiota has not yet been fully defined. Interest in bacterial transmission via the skin has been limited to the spread of pathogens; however, most skin microorganisms can be classified as both commensal and pathogenic, as is the case for Cutibacterium acnes, which is commensal in almost all patients but also causes acne (1).

Skin microbiota can be transmitted by direct contact but is also released into the atmosphere through the desquamation process. The environment is an almost infinite source of microorganisms suspended in the air and water systems or deposited on surfaces (2), where individuals exchange microorganisms as donors and recipients. The current SARSCoV-2 pandemic has highlighted the importance of determining certain microorganisms' skin transmission ability (3), particularly the high transmission between individuals in enclosed and crowded spaces such as public transport and swimming pools $(2,4,5)$. After being transmitted, the foreign microorganism can colonize the skin, sometimes causing an infection. The epidermis also acts as a platform for transmission to other individuals/environments. While differences in bacterial transmission capacity have been extensively studied, there are still unknown human factors favoring or limiting the transmission of exogenous bacteria by the skin.

Continuous external microbial exposure ensures the frequently transient diversity of the skin microbiome. In the hospital setting, the skin microbiome's (both for patients and healthcare workers) should be carefully controlled, as it is a key source for transmission events involving pathogenic bacteria. In fact, nosocomial infection often follows skin colonization by antibiotic multiresistant pathogenic bacteria. Hand washing by healthcare workers is still the best strategy for preventing the transmission of nosocomial pathogens, as has been demonstrated for Clostridioides difficile whose spores are resistant to the action of alcohol gels and standard disinfectants (6) and should be eliminated by shedding through standardized structured washing techniques (7).

\section{EPIDERMIS, THE BORDER WITH THE MICROBIAL ENVIRONMENT}

Our epidermis, the outermost side of the skin that covers $2 \mathrm{~m}^{2}$ on average, is not only exposed to a multiplicity of environmental organisms but also repeatedly makes contact and rubs against contaminated natural and artificial surfaces. The skin is a compartmentalized habitat, with specific microecological spaces such as keratinized space, sebaceous glands, and apocrine and eccrine glands where the bacterial density can differ considerably. There is also a critical epidermis-mucosal border, where mucosal microbial populations can coalesce with those established on the epidermal surface.

Despite the considerable increase in recent years in our knowledge of human microbiota, more investigation is needed into the interactions between the two microbial worlds of mucocutaneous junctions, from the point of view of biochemistry, microecology, and immunology (8). It seems clear that there is no sharp border but rather a gradient of conditions, likely dependent on physical variables such as humidity and temperature. These transitional areas are obvious in the lips, where we observe the non-keratinized epithelium of the labial mucosa transitioning to the buccal mucosa, with surfaces changing with age (9-11). Similar "borders" occur at the eyes, rectum, and vaginal mucosa and the neighboring keratinized epidermis. The microbiota at these borders has been poorly characterized.

The common use of fingers for exploring and washing mucosal orifices and during sexual activities is another important source of interactions between epidermal and mucosal microbes. Artificial mucosal-epidermis interfaces are frequently created in surgery (e.g., in ileostomies), sometimes with pathogenic consequences (12). In contrast, certain less exposed skin regions, such as interdigital and other skin folds, could constitute a potential healthy microbiome reservoir for recolonization of altered epidermal communities.

The microbial dialogue with the skin's immune system, both with the innate and adaptive cells, determines the tolerance or inflammation response. Although the response to microbial infections is well known, the determinants of a tolerance status are not. Dermatological research is currently focused on the interplay between the immune system and skin microbiota for diseases such as acne and seborrheic dermatitis (13). In these skin conditions, the pathogenic process is probably based on an excessive response of the local innate immunity against members of commensal microbiota, including bacteria such as Cutibacterium acnes, fungi, as Malassezia furfur, and viruses, as Merkel cell polyomavirus or herpesvirus.

A proinflammatory gut microbiota has been reported in patients with alopecia areata universalis (14), and there have been supporting epidemiological hypotheses such as the relationship between rosacea and Parkinson's disease on one hand and the skin-gut-brain axis on the other (15). Detailed studies of the local microbiome, such as the follicular microbiome, provide valuable information on the etiopathogenesis of chronic inflammatory diseases such as primary cicatricial alopecia and facilitates their understanding and classification (16). There has recently been major interest in microbiota composition as a predictor of drug response, particularly for the gut ecosystem and immunotherapy in melanoma, and it has been proposed the transference of fecal microbiota from immunotherapy responders to non-responders $(17,18)$. 


\section{THE EPIDERMAL MICROBIOME AND MODULATION STRATEGIES}

Is the epidermal microbiome representative of the dermal microbiome? Table $\mathbf{1}$ shows the bacterial genera which are shared in the dermal and epidermal compartments. In general, bacterial composition of the stratum corneum does not significantly differ from that of the full skin $(20,21)$. Sampling by swabbing therefore yields analogous results to sampling by tapping (22). The "constant" epidermal microbiome is a minority subset of the dermal microbiome, which constitutes a "real microbiota", extremely stable and universal in human hosts (19), where bacteria are adapted to the nutritional conditions of the dermal compartment. However, the shared bacteria are much more abundant in number in the epidermis, which also contains a high density of diverse and transient bacterial organisms, as expected by the frequency of environmental contacts, and consequently variable among individuals. Given that our focus is on transmission, we will not go into detail on the detailed skin microbiome composition, a topic that has been covered by other authors $(21,23,24)$.

At birth, single clones of a variety of microorganism colonize human skin. The environmental pressures and particular conditions experienced by the individual lead to microevolutions that result in lineage diversification, even in commensal S. epidermidis (25). During diversification, commensal microbiota can experience genetic acquisition or loss after punctual interactions with the transient transmitted bacteria. In addition, virulent and antibiotic-resistant clones, such as the Panton-Valentine leukocidin-producing methicillin-resistant $S$. aureus clone USA300, are habitually transmitted by skin contact and cause major outbreaks $(26,27)$.

The pathogenicity of particular $C$. acnes lineages has been reported not only in acne but also in systemic diseases such as prostatitis/prostate cancer, synovitis-acne-pustulosishyperostosis-osteitis syndrome, sarcoidosis, sciatica, and implant-associated infections. Skin microbiota transplantation from a healthy donor has been proposed to treat dermatologic conditions $(28,29)$, mainly to eradicate virulent $C$. acnes and $S$. aureus clones, or at least to replace the bacteria with non-virulent ones. The utility of bacteriophages for skin infections, particularly those caused by Pseudomonas in extensive burns, has recently been recently reviewed (30).

\section{BACTERIAL NUTRITION AND GROWTH ON THE EPIDERMIS}

Lipids excreted by sebaceous glands (frequently in the facial epidermis) contain anti-bacterial substances and protective compounds and are a nutrition source (31). Gram-positive bacteria in the skin, mainly Staphylococcus and Cutibacterium, release exoenzymes to enhance the recovery of nutrients from the environment, particularly proteases for amino acid liberation from skin proteins such as keratins, collagen and elastin (32). For instance, lipase production for triglyceride lipid degradations is significantly higher around comedones, causing inflammation in acne $(21,33)$. Other exoenzymes include bacterial hyaluronidase, which enable the obtention of glucuronic acid and N-acetyl-Dglucosamine from long-chained hyaluronic acid, and DNase, which likely degrades the extracellular DNA from apoptotic keratinocytes or corneocytes. C. acnes can induce keratinocyte autophagy by stimulating the CD36-CD14-TLR2/4-TLR6 signaling module, triggering ROS generation through nicotinamide adenine dinucleotide phosphate oxidase and the TRAF6-ECSIT-NLRX1 pathway and evoking mitochondrial dysfunction $(34,35)$. However, we still lack the full picture of microbial nutrition in the skin, particularly regarding the role of protocooperative actions among bacterial species in nutrient exploitation.

The critical factors of bacterial nutrition and growth in the epidermis are $\mathrm{pH}$ and water availability, which also determine the concentration of free amino acids and lactate. For example, the water content of the stratum corneum of Japanese individuals (as measured by Raman spectroscopy) ranges from $30 \%$ at the

TABLE 1 | Bacterial microbiota in the epidermal and dermal compartments.

\begin{tabular}{|c|c|c|}
\hline $\begin{array}{l}\text { Epidermal-Dermal Genera } \\
\text { Not Phylum } \\
\text { Proteobacteria }\end{array}$ & $\begin{array}{l}\text { Epidermal-Dermal } \\
\text { Genera Phylum } \\
\text { Proteobacteria }\end{array}$ & $\begin{array}{c}\text { Epidermal-Dermal } \\
\text { Genera } \\
\text { Anaerobes }\end{array}$ \\
\hline Corynebacterium & Pelomonas & Finegoldia \\
\hline Staphylococcus & Acinetobacter & Peptoniphilus \\
\hline Micrococcus & Moraxella & Anaerococcus \\
\hline Streptococcus & Pseudomonas & Blautia \\
\hline Paracoccus & & Porphyromonas \\
\hline Brachyobacterium & & Fenollaria \\
\hline Kocuria & & Veillonella \\
\hline Dietzia & & Cylindrospermum \\
\hline Actinomyces & & Prevotella \\
\hline Brevibacterium & & Dialister \\
\hline Tepidimonas & & Bifidobacterium \\
\hline
\end{tabular}

This Table was inspired by the publication referenced as Bay et al. (19).

Epidermal microbiota is much more abundant and variable (strongly affected by environmental contacts) than dermal microbiota. A subset of most frequent members of the epidermic microbiota constitute a very stable and universal (preserved in different individuals) dermal bacterial community, adapted to the nutrients of the dermal compartment. In the boxes below, listed by frequency, the epidermal genera with high representation in the dermal compartment are highlighted in bold characters. 
surface to $70 \%$ in the deeper layers (36). Prolonged water exposure significantly increases the epidermal water content; however, the external part of the stratum corneum gradually dries out after the forced hydration is discontinued (36). The water content of the skin surface is then mainly based on excretion by eccrine sweat glands. However, free amino acids, glycerol, sphingolipids and particularly metabolites of filaggrin, a large protein bound to lipids and keratin, such as urocanic acid and pyrrolidone carboxylic acid, also function in the outer skin as natural moisturizing factors, able to absorb large amounts of water and maintain a low $\mathrm{pH}$ (37). The epidermal water content depends on age, anatomical site and season. Certain molecules (such as teichoic acids) on the external surface of Gram-positive bacteria can produce local proinflammatory effects (38), which results in greater water availability resulting from increased vascularity. Osmolarity increases with water paucity. Water tends to be retained in the epidermal keratinocytes outer layer, particularly in the valleys where it is protected from evaporation; in addition, under osmotic stress more water-channels are produced, as aquaporin-3 (39). The skin's retention of transmitted bacteria depends strongly on water (40). Sweat increases water availability, transports molecules with bacterial impact, and facilitates bacterial transmission through signals contained in their extracellular vesicles.

\section{BACTERIAL DEATH ON THE EPIDERMIS}

Keratinocytes contribute to the innate immune response system by sensing microbial cell density by detecting pathogenassociated molecular patterns (PAMPs) through pattern recognition receptors (PRRs) (21). Such detection results in the induction of release of cytokines, chemokines, and antimicrobial peptides (AMPs) such as human beta-defensins HBD-1, HBD-2, and HBD-3, cathelicidin LL-37, and the antimicrobial proteins RNase 7 (from the RNase A superfamily) and Perforin-2, the last being able to kill intracellular organisms (41-43).

The response is modulated by molecules on the surface or those released by commensal organisms (44). The conditions favoring the overgrowth and immunological tolerance of skin commensals are frequently those that are also beneficial for the growth of certain skin pathogens (Figure 1). The "bacterial overgrowth" signal is therefore likely triggered by commensals, resulting in decreased commensal density; however, this decrease is deleterious for less numerous pathogens. The overgrowth of skin commensals likely releases immunity-stimulating signals, including structural bacterial molecules such as teichoic acids or proteins released from the bacterial cell wall, microbial-secreted substances such as porphyrins, and molecules, as oleic acid, resulting from the bacterial metabolism of local lipid substrates (45). Overgrowth is eventually followed by intracellular engulfment and the release of more signaling molecules such as complement and interleukin-1. Perforin-2 upregulation following $S$. epidermidis overgrowth increases the intracellular killing of $S$. aureus (41). The innate lymphoid cells regulate the production of antimicrobial lipids (such as palmitoleic fatty acids), reducing the population density of Staphylococcus and, in general, all Gram-positive bacteria (46).

In normal conditions, a "normal"-sized population of commensals (such as S. epidermidis) stimulates only the innate defense system (47). Pathogens such as S. aureus have evolved mechanisms for subverting immune stimulation, such as modifying their PAMPS (48); however, these bacterial protection mechanisms are expected to be effective only after reaching a cell-density threshold.

The strategy of eliminating pathogens by regulating commensal overgrowth (Figure 1) is based on the differences between highly adapted organisms (commensals, those with large populations) and less adapted organisms (occasional pathogens, those with small populations) that compete for the same resources (47). Commensals are better endowed to reconstruct the original population density after a challenge. In fact, the population density of commensals is by itself a limiting factor for pathogenic colonization, either indirectly (e.g., by nutritional competition) or directly (e.g., antagonistic substances). Direct antagonism between commensal and pathogenic staphylococci is frequently mediated by secondary metabolites such as low molecular weight bacteriocins, frequently of the lantibiotics type, the equivalent to microcins in intestinal Enterobacterales $(49,50)$. Lantibiotics released from commensal Staphylococcus are synergistic with the human cathelicidin antimicrobial peptide LL-37 in reducing $S$. aureus populations (51). S. epidermidis might also interfere with $S$. aureus biofilm-type colonization by expressing the serine-type protease Esp. In fact, protection against $S$. aureus involvement in atopic dermatitis by increasing the density of commensal microbes is being explored. The immunological response against pathogens might in fact depends on resident commensals. The shedding of the stratum corneum acts as a sink for microorganisms adhered to the skin surface; however, these organisms persist by colonizing the deeper layers of the epidermis thereby keeping the population density stable.

\section{GRAM-POSITIVE VERSUS GRAM-NEGATIVE}

The conditions of low moisture, high osmolarity, low $\mathrm{pH}$, and AMPs presence clearly favors organisms with a thick peptidoglycan envelope and lacking an outer membrane, as well as Gram-positive organisms, with the interesting exception of Enterococcus species, which are not usually found in the epidermis. Gram-negative organisms are not permanent colonizers of the outer skin, with the exception of Acinetobacter in moist intertriginous areas. In experimental transmission studies, Gram-positive organisms, such as E. faecium and $S$. aureus, exhibited the highest transmission efficiency, whereas Gram-negative organisms were less efficient, particularly E. coli, which had the lowest transmission rate (52). The recovery of phages from Gram-negative Proteobacteria might simply reflect the occasional, transient colonization of these microorganisms, with the possible exception of individuals with primary 


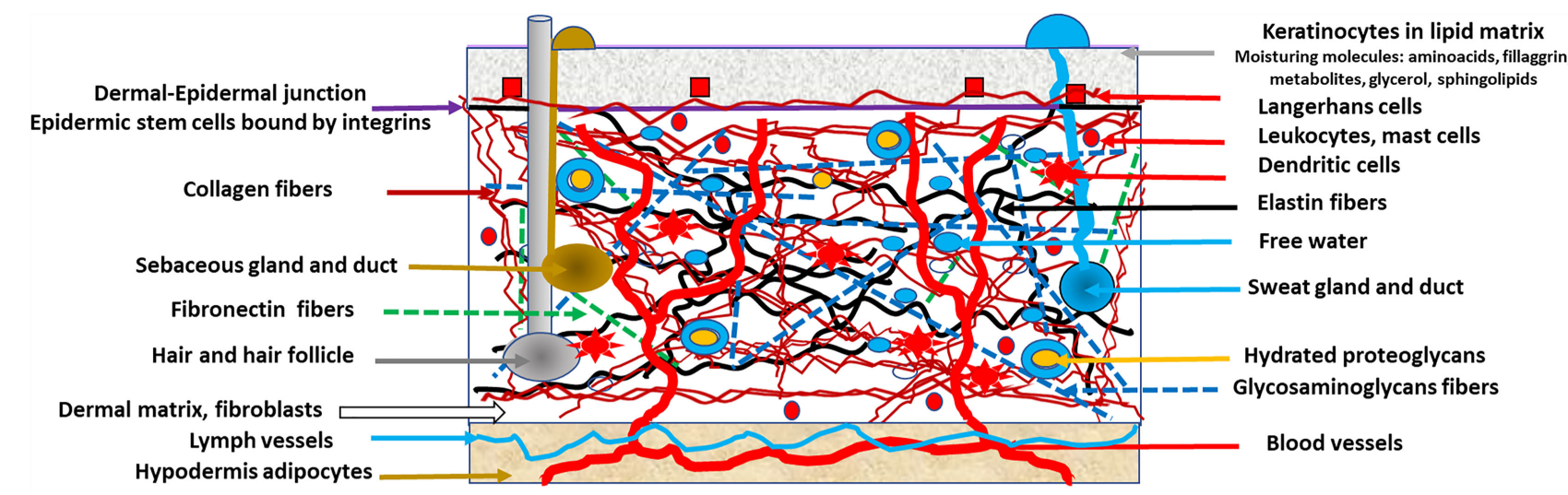

Keratinocytes in lipid matrix metabolites, glycerol, sphingolipids Langerhans cells Leukocytes, mast cells Dendritic cells astin fibers ree water Bacterial overgrowth
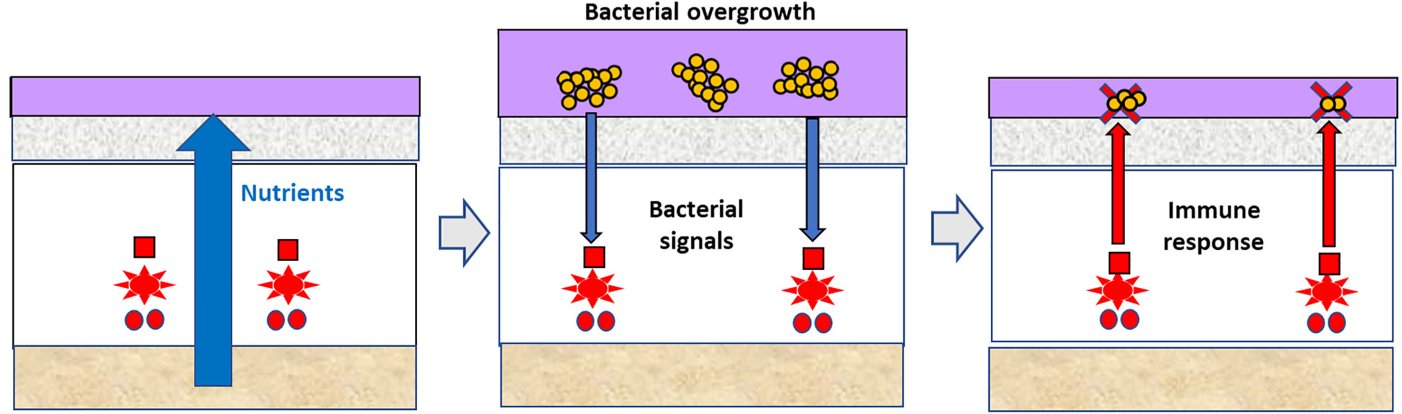

FIGURE 1 | The hypothesis of indirect epidermal bacterial clearance of a pathogen. Up in the figure, a schematic view of the skin is presented, particularly of the components of the dermal compartment, determining the commensal microbiota of the epidermis. Below, the indirect epidermal bacterial clearance of a pathogen (clusters of yellow circles) in the violet layer (surface commensal microbiota). Conditions facilitating the growth of commensals (vertical blue thick arrow) also favors pathogens, but the commensals overgrowth stimulate (narrow blue arrows) the defense system based on cellular local immune innate response involving cellular (red squares, circles, stars) and glands secretion. Antimicrobial defense (red arrows) reduces the overall bacterial density, but the lower-numbered pathogens are eliminated (red X symbol), whereas the dominant commensal population is reduced to its normal density (sequence from the second to the third box at the bottom).

immunodeficiencies $(53,54)$. However, some commensal species from the Phylum Proteobacteria, as Pelomonas, are consistently present in the dermal compartment, and might migrate to the epidermis (Table 1). Important potential human pathogens such as Enterobacterales and Enterococcus are rare in normal epidermis, despite expected frequent external contamination from the intestinal microbiota. It is certainly plausible that Gram-positive commensals might elicit the production of human antimicrobial peptides able to eradicate small populations of Gram-negative bacteria, using the strategy illustrated in Figure 1.

Skin osmolarity also favors Gram-positive bacteria. Certain Proteobacteria can be detected by $16 \mathrm{~S}$ rDNA sequencing from the skin surface, including Acinetobacter, Enterobacter, Klebsiella, Pseudomonas, Serratia and Sphingomonas, all of them environmental organisms and likely transient "skinlanding" bacteria. In short, the epidermis should not be considered a niche for Enterobacterales or Enterococcus, given that it does not support the significant growth of these critical human pathogens (55). If these organisms are just transiently bound to the epidermis by weak unspecific adhesion, the possibility of being transmitted between hosts could be enhanced.
A rarely considered aspect of the epidermal bacterial microecology (and transmission) is the spatial structure of bacterial cells, ranging from homophilic clumps to larger biofilms. In particular, Staphylococcus tends to clump into multicellular aggregates (staphyle is the Greek name for a bunch of grapes), facilitating adhesion to the skin and likely colonization. The intercellular homophilic bonds of Staphylococcus depend on a polycationic polysaccharide intercellular adhesin; however, the role of cell wall-anchored proteins (self-aggregating molecules) appears to be critical in the process. These proteins (e.g., the bacterial surface serineaspartate repeat protein $\mathrm{SdrC}$ ) might also be considered a multifunctional adhesin involved in hydrophobic interactions with surfaces. In fact, clumping-negative $S$. aureus mutants are less adhesive to surfaces, including keratinocytes (56).

The interaction between bacteria and the colonizable surfaces is mediated by cell appendages and specific molecules located at the cell surface. In particular, a large variety of adhesins assures the close contact required to exploit structured environments. Many of these adhesins are involved in the attachment to the host tissues including skin, and also contribute to in the formation of interbacterial interactions resulting in the formation of local biofilms (bacterial multicellular aggregates), increasing the 
resilience (permanence) of adhered bacterial populations. The molecular determinants mediating specific bacterial adhesion to the outer layers of the epidermis remain scarcely investigated for most bacterial taxa. On the contrary, excellent information is accessible for some pathogenic Gram-positive bacteria, including a thematic Research Topic in Frontiers in Microbiology (57). Seminal reviews are available on Staphylococcus adhesion mediated by surface proteins, mostly comprising the hydrophobic LPXTG transmembrane motif assuring cell-wall anchoring. Many of these surface components recognize adhesive matrix molecules as fibronectin, vitronectin, laminin, fibrinogen or elastin, the MSCRAMM family. Fibronectinbinding adhesins (FnBPA and FnBPB in S. aureus) regulated by agr and sar operons, are critical in the adhesion to the squamous epithelium (58-61).

Interestingly, Staphylococcus LPXTG proteins and some extracellular adherence proteins also promote bacterial internalization by keratinocytes, assuring the permanence of the bacterial population in the epidermal compartment (62). Populational resilience is enhanced by biofilm formation, involving, among others, Aap and SdrF proteins (63). Interbacterial adhesion on the epidermis is also favored by the small basic protein (Sbp). This protein favors the formation of amyloid fibrils structuring the biofilm matrix derived from the effect of adhesins, comprehending microbial polysaccharide (mostly $\beta$-1-6-linked $\mathrm{N}$-acetylglucosamine), intercellular adhesin surface proteins, DNA, and proteins from dead cells (60). Other surface components of Gram positives, as teichoic acids, also contribute to skin adhesion (64).

Consider that in $S$. aureus there are 24 different LPXTG adhesins with different specificities and roles. S. epidermidis expresses more than 10 adhesins $(60,61)$. Staphylococcus lugdunensis is also a frequent commensal in the outer layers of the skin and contains the LPXTG protein SrtA $(65,66)$.

In the case of Cutibacterium bacteria, mostly probably originated in the sebaceous glands-ducts where they have their niche $(67,68)$, they migrate to the epidermis and remain attached by their fibronectin-binding surface proteins, also inducing keratinocytes internalization, which assures the local permanence $(35,62)$.

The skin adhesion of bacterial spores, including those of pathogenic organisms such as $C$. difficile, is poorly known, but approximately $5 \%$ of hospital health workers are carriers of these organisms $(69,70)$. Future advances in the "ecology of adhesion" might result from applying confocal laser scanning microscopy, given that it has been used for human mucosal surfaces (71).

\section{THE ROLE OF THE EPIDERMIS IN TRANSMITTING HUMAN PATHOGENS}

Although certain key human pathogens are not permanently established on the surface of the normal epidermis, they use the surface as a platform for host-to-host transmission. In the case of Enterobacterales, the hands of intensive care unit (ICU) staff are frequently (nearly 20\%) contaminated by the same Klebsiella clones that infect patients; however, the absolute count by culture does not exceed $10^{3}$ per hand, and the survival time was estimated at approximately $2-3 \mathrm{~h}$ (72). In fact, in abiotic dry surfaces, such as computer keyboards in the ICU used by nurses and doctors, only Gram-positive skin bacteria are recovered, mostly S. epidermidis (73). As in the case of ICU health workers, environmentally linked individuals tend to share bacterial organisms. In fact, easy transmission of antibiotic-resistant Enterobacterales, presumptively by hand contamination, occurs among household members and individuals who visit friends and relatives (74-76). In closed communities, a common community epidermal microbiota is expected.

Most of the published works on the epidermal transmission of human pathogens are derived from hand-washing studies, one of the key "rituals" in preventive medicine. Although the efficacy of hand washing is extremely difficult to estimate, hand washing is undeniably highly effective in decreasing the risk of contaminating sterile tissues, mechanical devices and food by low-numbered pathogenic bacteria, as shown in the seminal work by Semmelweis (77). The effectiveness of hand washing in eliminating microbial organisms is inversely proportional to the skin's bacterial load and frequently has only a marginal, transient effect on heavily inoculated fingertips (78). It is noteworthy that Semmelweis discarded as irrelevant the use of microscopes to explain his results (77). That resulted in an epistemologically utilitarian "Semmelweis Complex" recommending that the focus be on efficacy and not the scientific reasons for explaining the effect. Such scientifically deleterious Complex remains very much alive in public health. To quote a modern reference, "studies on practical and efficient means to increase compliance with hand hygiene guidelines and to influence behavior surely are needed more than are elaborate and sophisticated studies on the effects of hand washing" (79). Such generalized "practical" view has delayed experimental studies, and consequently there are numerous issues in handwashing biology that are unknown or poorly understood. For instance, if the hand's commensal bacteria can prevent the growth of potential pathogens, the controlled reduction of these commensals might be more advisable than full eradication (80). Increasing our knowledge of the biology of epidermal bacterial transmission appears to be the only option for improving our interventions.

\section{EXPERIMENTAL BACTERIAL TRANSMISSION}

The biology of hand-to-hand transmission is a recent field of research. In a seminal study published in 2014 (81), broth suspensions of potentially pathogenic well-defined clones of E. faecium, a non-skin commensal Gram-positive organism, were gently deposited and spread on both thumb tip surfaces (approx. $10^{7}$ cells over $1.32 \mathrm{~cm}^{2}$ ) of 30 healthy volunteers (4 experiments per individual, spread over 6 months). After complete drying, the organisms from a sample surface of 0.78 $\mathrm{cm}^{2}$ on one of the thumbs were suspended by shaking them in a saline solution. The second contaminated thumb was put in close 

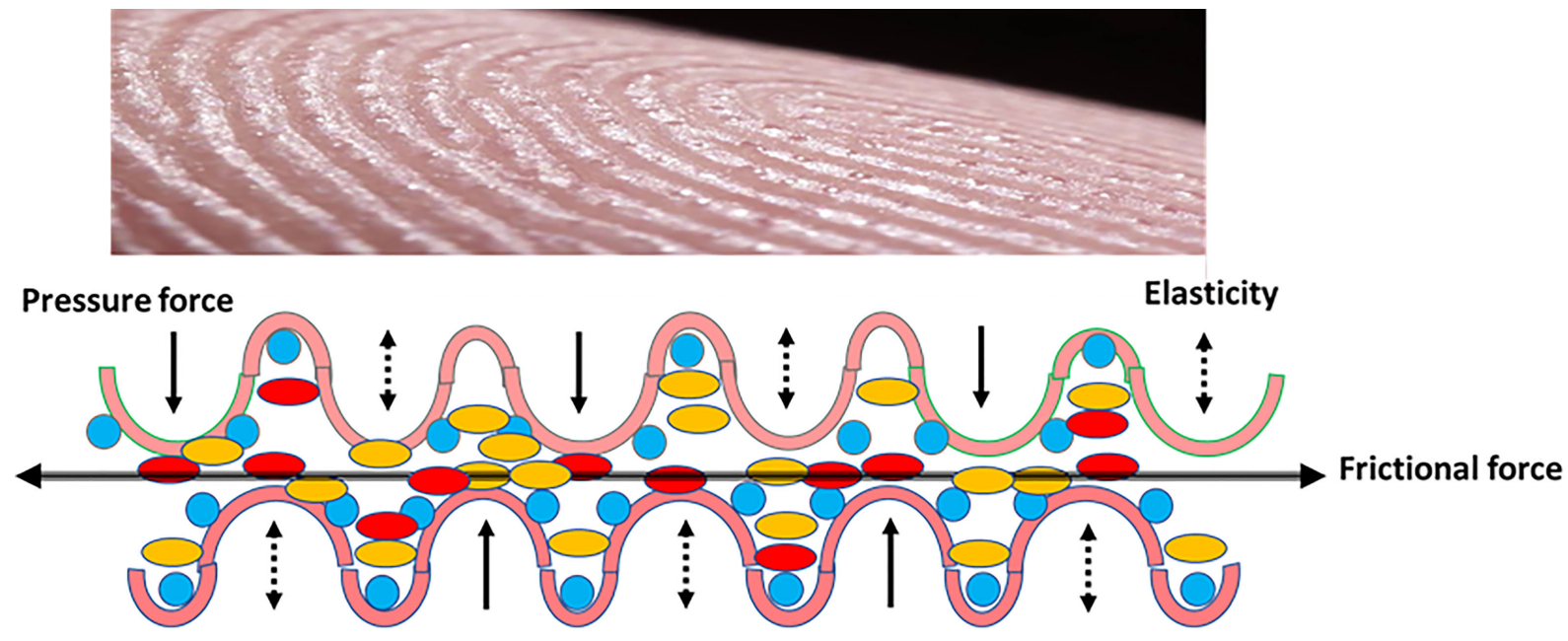

Pressure force Elasticity

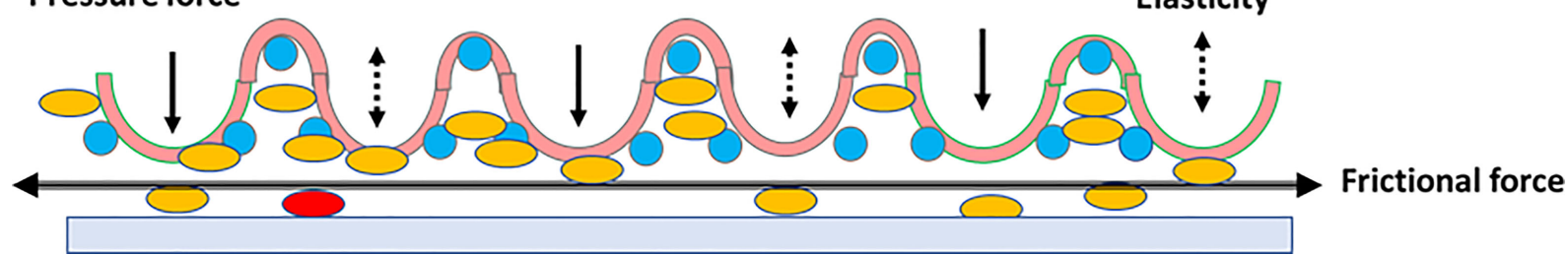

FIGURE 2 | Epidermis tribology. Up in the figure, the surface of a finger pad, showing the epithelial pad crests. Below, two rubbing series of friction (beheaded arrow) finger pad crests. Because of the pressure and frictional forces (black arrows), and elasticity of the dermal compartment, the (yellow) bacteria of the upper epithelium frequently migrate to the lower epithelium, and only some of the (red) bacteria are transmitted to the green epithelium. The asymmetry of transmission might be due to microecological differences, for instance water content (blue circles). Down in the slide, if the epidermis is rubbed on a smooth surface, the

transmission is much less effective.

static contact (with minimal pressure and preventing twists or wipes) with the index fingertip of the other hand of the same individual for $10 \mathrm{~s}$, and the transmitted organisms were also suspended. Over several steps involving the fingers of both hands, a quantitation curve of the proportion of finger-tofinger transmission was obtained. The bacterial count showed an exponential decay in sequential finger-to-finger transfers in most of the volunteers, typically a decay of $1.5 \mathrm{log}$ in successive counts. This result is consistent with that obtained in similar experiments on skin bacterial survival and hand transmission (82-84). Interestingly, in the E. faecium experiment, the frequency distribution of the exponential decay parameter estimated for all individuals clearly showed an asymmetrical right tail containing an overrepresentation of high transmitter individuals ( $13 \%$ of the volunteers) with their epidermis exponential decay parameters close to zero. A variable transmission rate of the various Enterococcus clones was also observed, supporting the suggestion that a number of bacterial variants (including Gram-negative bacteria, such as Proteobacteria) could be better adapted than others to the environmental skin circulation $(81,85)$. A further analysis of the data proposed 3 transmission efficiency categories: poor, medium, and high finger-to-finger bacterial transmitters. All 10 male volunteers were classified as poor or high intrahost transmitters, whereas almost all 20 of the female participants were grouped in the medium category (53).

Experimental fingertip transmission studies extended to interhost transmission have shown that the success of the transmission chain depends on the position of a poor transmitter in the series. Poor-transmitter volunteers had the ability to cut off the transmission chain independently of their position (53). Certainly, these preliminary observations might foster further research to determine the individual risks of foodborne transmission and healthcare workers.

\section{THE BASIS FOR INDIVIDUAL VARIABILITY IN BACTERIAL TRANSMISSION}

The density and diversity of skin commensal bacteria might affect the fate of pathogenic bacteria contacting the surface. In contrast to the low variability of dermal microbiota across humans, the epidermis shows a higher polymorphic set of bacterial species, probably because they reflect the host's lifestyle and changing environment (e.g., altitude or temperature) $(19,86)$. Interindividual genetic differences in epidermal microbes cannot be totally ruled out, given that 
variations occur with organisms in fish skin and that of sea mammals $(87,88)$. In humans, these genetic differences might occur $(45,89,90)$, but the effects of race have not been sufficiently evaluated, although peculiarities of the skin microbiota of Chinese populations have been suggested (90). Genetics and sex can affect the density of eccrine, apocrine, and sebaceous glands determining the physical, chemical, adhesive, nutritional, and immunological status of the epidermal surface and thereby the density and type of organisms. The influence of age, stress, and hormonal status also cannot be overlooked. In the above-mentioned experiments regarding E. faecium finger-tofinger transmission, no significant association for transmission decay was found between fingertip temperature measurements and finger pressure $(53,81)$. There is a need for studying the intraindividual and interindividual transmission of organisms from various epidermic sites, such as sebaceous areas (e.g., face and back), moist areas (e.g., the armpits and the webbed parts of the fingers/toes), dry areas (e.g., forearms and buttocks), and sites containing varying densities of hair follicles, skin folds, and skin thicknesses. The role of epidermal friction ridges is a possible line for further research into the biology of the epidermal transmission of bacteria.

\section{TRIBOLOGY OF SKIN: FRICTION RIDGES ON THE FINGERTIPS}

Tribology is the science of interacting surfaces in relative motion, including, as said before, friction, wear and lubrication. Tribological phenomena occur on a large scale, and include microbiotribology, as in the case of homophilic bacterial cell interactions, giving rise to frictional phenomena, possibly creating electromagnetic fields that influence collective and individual cell behavior $(91,92)$. For human surfaces, a greater understanding is needed of the nonlinear effects of plasticity, adhesion, friction, wear, lubrication and surface chemistry, all of which play a part in skin tribology (Figure 2) (93).

Fingertips, which are critical surfaces in human-to-human bacterial transmission, are covered with friction skin $(94,95)$. Papillary ridges in friction skin likely evolved to assist in grasping and holding onto objects and are important in the biology of

\section{REFERENCES}

1. Leheste JR, Ruvolo KE, Chrostowski JE, Rivera K, Husko C, Miceli A, et al. P. Acnes-Driven Disease Pathology: Current Knowledge and Future Directions. Front Cell Infect Microbiol (2017) 7:81. doi: 10.3389/ fcimb.2017.00081

2. Leung MHY, Tong X, Bøifot KO, Bezdan D, Butler DJ, Danko DC, et al. Characterization of the Public Transit Air Microbiome and Resistome Reveals Geographical Specificity. Microbiome (2021) 9(1):112. doi: 10.1186/s40168-021-01044-7

3. Anderson CE, Boehm AB. Transfer Rate of Enveloped and non-Enveloped Viruses Between Finger Pads and Surfaces. Appl Environ Microbiol (2021) 87(22):e0121521. doi: 10.1128/AEM.01215-21

4. Kang K, Ni Y, Li J, Imamovic L, Sarkar C, Kobler MD, et al. The Environmental Exposures and Inner- and Intercity Traffic Flows of the primates and koalas (96). The equilibrium between friction ridges and optimal hydration (eccrine glands) of the keratin layer maximizes friction (97). In humans, skin friction and microbial transmission depend on the tribological configuration; the surface roughness and the finger pad sweat rates. Age modifies friction forces by reducing skin thickness, dermal elasticity, and by ridge flattering, possibly in relation with collagen reduction (98). Dynamic optical coherence measurements by tomography will likely be essential for determining the frictional behavior of human finger pads (99, 100). We expect these studies to be applied soon to the humanto-human transmission of microorganisms $(101,102)$. Nothing is known about the triboelectric effects of ridge friction (which creates magnetic fields) on bacterial adhesion and repulsion. Multivariate models for predicting the frictional behavior of human skin, thereby identifying "high-transmitter" populations (81), could have obvious applications in public health, from food microbiology to hospital-based cross-infections.

\section{AUTHOR CONTRIBUTIONS}

FB and RdC wrote the manuscript; CS, DMM and LB provided information on microbiology, SGV and OMMA supervised and provided dermatological information. The final manuscript is approved by all authors. All authors contributed to the article and approved the submitted version.

\section{FUNDING}

This work was supported by the Instituto de Salud Carlos III PI20/00164 to RdC, and REIPI (RD16/0016/0011) actions, cofinanced by the European Development Regional Fund "A way to achieve Europe" (ERDF). FB was supported by InGEMICS-CM (B2017/BMD-3691), funded by Comunidad de Madrid (Spain) and European Structural and Investment Funds; and by the CIBER in Epidemiology and Public Health, CIBERESP (CB06/02/0053), integrated in the Spanish 2013-2016 I+D+i State Plan and funded by Instituto de Salud Carlos III.

Metro System may Contribute to the Skin Microbiome and Resistome. Cell Rep (2018) 24(5):1190-1202.e5. doi: 10.1016/j.celrep.2018.06.109

5. Shuai X, Sun Y, Meng L, Zhou Z, Zhu L, Lin Z, et al. Dissemination of Antibiotic Resistance Genes in Swimming Pools and Implication for Human Skin. Sci Total Environ (2021) 794:148693. doi: 10.1016/j.scitotenv.2021. 148693

6. Jabbar U, Leischner J, Kasper D, Gerber R, Sambol SP, Parada JP, et al. Effectiveness of Alcohol-Based Hand Rubs for Removal of Clostridium difficile Spores From Hands. Infect Control Hosp Epidemiol (2010) 31 (6):565-70. doi: 10.1086/652772

7. Deschênes P, Chano F, Dionne LL, Pittet D, Longtin Y. Efficacy of the World Health Organization-recommended Handwashing Technique and a Modified Washing Technique to Remove Clostridium difficile From Hands. Am J Infect Control (2017) 45(8):844-8. doi: 10.1016/j.ajic. 2017.04.001 
8. Binnie WH, Lehner T. Histology of the Muco-Cutaneous Junction at the Corner of the Human Mouth. Arch Oral Biol (1970) 15(8):777-86. doi: 10.1016/0003-9969(70)90041-5

9. Dimond RL, Montagna W. Histology and Cytochemistry of Human Skin. The Nose and Lips. Arch Dermatol (1976) 112(9):1235-44. doi: 10.1001/ archderm.112.9.1235

10. Kobayashi H, Tagami H. Distinct Locational Differences Observable in Biophysical Functions of the Facial Skin: With Special Emphasis on the Poor Functional Properties of the Stratum Corneum of the Perioral Region. Int J Cosmet Sci (2004) 26(2):91-101. doi: 10.1111/j.0412-5463.2004.00208.x

11. Kobayashi H, Tagami H. Functional Properties of the Surface of the Vermilion Border of the Lips are Distinct From Those of the Facial Skin. Br J Dermatol (2004) 150(3):563-7. doi: 10.1046/j.1365-2133.2003.05741.x

12. Rodrigues FP, Novaes JAV, Pinheiro MM, Martins P, Cunha-Melo JR. Intestinal Ostomy Complications and Care. In: Gastrointestinal Stomas. London, United Kingdom: IntechOpen (2019).

13. Dréno B, Araviiskaia E, Berardesca E, Gontijo G, Sanchez Viera M, Xiang LF, et al. Microbiome in Healthy Skin, Update for Dermatologists. J Eur Acad Dermatol Venereol (2016) 30(12):2038-47. doi: 10.1111/jdv.13965

14. Moreno-Arrones OM, Serrano-Villar S, Perez-Brocal V, Saceda-Corralo D, Morales-Raya C, Rodrigues-Barata R, et al. Analysis of the Gut Microbiota in Alopecia Areata: Identification of Bacterial Biomarkers. J Eur Acad Dermatol Venereol (2020) 34(2):400-5. doi: 10.1111/jdv.15885

15. Moreno-Arrones OM, Ortega-Quijano D, Perez-Brocal V, Fernandez-Nieto D, Jimenez N, de Las Heras E, et al. Dysbiotic Gut Microbiota in Patients With Inflammatory Rosacea: Another Clue Towards the Existence of a Brain-Gut-Skin Axis. Br J Dermatol (2021) 185(3):655-7. doi: 10.1111/ bjd.20411

16. Moreno-Arrones OM, del Campo R, Saceda-Corralo D, Jimenez-Cauhe J, Ponce-Alonso M, Serrano-Villar S, et al. Folliculitis Decalvans Microbiological Signature is Specific for Disease Clinical Phenotype. J Am Acad Dermatol (2020) 85:1355-7. doi: 10.1016/j.jaad.2020.10.073

17. Gopalakrishnan V, Spencer CN, Nezi L, Reuben A, Andrews MC, Karpinets TV, et al. Gut Microbiome Modulates Response to Anti-PD-1 Immunotherapy in Melanoma Patients. Science (2018) 359(6371):97-103. doi: $10.1126 /$ science.aan 4236

18. Baruch EN, Youngster I, Ben-Betzalel G, Ortenberg R, Lahat A, Lior K, et al. Fecal Microbiota Transplant Promotes Response in ImmunotherapyRefractory Melanoma Patients. Science (2021) 371(6529):602-9. doi: $10.1126 /$ science.abb5920

19. Bay L, Barnes CJ, Fritz BG, Thorsen J, Restrup MEM, Rasmussen L, et al. Universal Dermal Microbiome in Human Skin. mBio (2020) 11(1):e0294519. doi: $10.1128 / \mathrm{mBio} .02945-19$

20. Ross AA, Hoffmann AR, Neufeld JD. The Skin Microbiome of Vertebrates. Microbiome (2019) 7(1):1-14. doi: 10.1186/s40168-019-0694-6

21. Byrd AL, Belkaid Y, Segre JA. The Human Skin Microbiome. Nat Rev Microbiol (2018) 16(3):143-55. doi: 10.1038/nrmicro.2017.157

22. Ogai K, Nagase S, Mukai K, Iuchi T, Mori Y, Matsue M, et al. A Comparison of Techniques for Collecting Skin Microbiome Samples: Swabbing Versus Tape Stripping. Front Microbiol (2018) 9:2362. doi: 10.3389/fmicb. 2018.02362

23. Cundell AM. Microbial Ecology of the Human Skin. Microb Ecol (2018) 76 (1):113-20. doi: 10.1007/s00248-016-0789-6

24. Rademacher F, Simanski M, Gläser R, Harder J. Skin Microbiota and Human 3D Skin Models. Exp Dermatol (2018) 27(5):489-94. doi: 10.1111/exd.13517

25. Zhou W, Spoto M, Hardy R, Guan C, Fleming E, Larson PJ, et al. HostSpecific Evolutionary and Transmission Dynamics Shape the Functional Diversification of Staphylococcus epidermidis in Human Skin. Cell (2020) 180(3):454-470.e18. doi: 10.1016/j.cell.2020.01.006

26. Popovich KJ, Green SJ, Okamoto K, Rhee Y, Hayden MK, Schoeny M, et al. MRSA Transmission in Intensive Care Units: Genomic Analysis of Patients, Their Environments, and Healthcare Workers. Clin Infect Dis (2021) 72 (11):1879-87. doi: 10.1093/cid/ciaa731

27. Mork RL, Hogan PG, Muenks CE, Boyle MG, Thompson RM, Sullivan ML, et al. Longitudinal, Strain-Specific Staphylococcus aureus Introduction and Transmission Events in Households of Children With CommunityAssociated Meticillin-Resistant S. aureus Skin and Soft Tissue Infection:
A Prospective Cohort Study. Lancet Infect Dis (2020) 20(2):188-98. doi: 10.1016/S1473-3099(19)30570-5

28. Paetzold B, Willis JR, Pereira de Lima J, Knödlseder N, Brüggemann H, Quist SR, et al. Skin Microbiome Modulation Induced by Probiotic Solutions. Microbiome (2019) 7(1):95. doi: 10.1186/s40168-019-0709-3

29. Perin B, Addetia A, Qin X. Transfer of Skin Microbiota Between Two Dissimilar Autologous Microenvironments: A Pilot Study. PloS One (2019) 14(12):e0226857. doi: 10.1371/journal.pone.0226857

30. Callewaert C, Knödlseder N, Karoglan A, Güell M, Paetzold B. Skin Microbiome Transplantation and Manipulation: Current State of the Art. Comput Struct Biotechnol J (2021) 19:624-31. doi: 10.1016/j.csbj.2021.01.001

31. Smith KR, Thiboutot DM. Thematic Review Series: Skin Lipids. Sebaceous Gland Lipids: Friend or Foe? J Lipid Res (2008) 49(2):271-81. doi: 10.1194/ jlr.R700015-JLR200

32. Mikx FH, De Jong MH. Keratinolytic Activity of Cutaneous and Oral Bacteria. Infect Immun (1987) 55(3):621-5. doi: 10.1128/iai.55.3.621625.1987

33. Loss M, Thompson KG, Agostinho-Hunt A, James GA, Mongodin EF, Rosenthal I, et al. Noninflammatory Comedones Have Greater Diversity in Microbiome and are More Prone to Biofilm Formation Than Inflammatory Lesions of Acne Vulgaris. Int J Dermatol (2020) 60(5):589-96. doi: 10.1111/ ijd. 15308

34. Holland KT, Greenman J, Cunliffe WJ. Growth of Cutaneous Propionibacteria on Synthetic Medium; Growth Yields and Exoenzyme Production. J Appl Bacteriol (1979) 47(3):383-94. doi: 10.1111/j.13652672.1979.tb01198.x

35. Megyeri K, Orosz L, Bolla S, Erdei L, Rázga Z, Seprényi G, et al. Propionibacterium acnes Induces Autophagy in Keratinocytes: Involvement of Multiple Mechanisms. J Invest Dermatol (2018) 138 (4):750-9. doi: 10.1016/j.jid.2017.11.018

36. Egawa M, Tagami H. Comparison of the Depth Profiles of Water and WaterBinding Substances in the Stratum Corneum Determined In Vivo by Raman Spectroscopy Between the Cheek and Volar Forearm Skin: Effects of Age, Seasonal Changes and Artificial Forced Hydration. Br J Dermatol (2008) 158 (2):251-60. doi: 10.1111/j.1365-2133.2007.08311.x

37. Feuillie C, Vitry P, McAleer MA, Kezic S, Irvine AD, Geoghegan JA, et al. Adhesion of Staphylococcus aureus to Corneocytes From Atopic Dermatitis Patients is Controlled by Natural Moisturizing Factor Levels. mBio (2018) 9 (4):e01184-18). doi: 10.1128/mBio.01184-18

38. Brauweiler AM, Goleva E, Leung DYM. Staphylococcus aureus Lipoteichoic Acid Damages the Skin Barrier Through an IL-1-Mediated Mathway. J Invest Dermatol (2019) 139(8):1753-1761.e4. doi: 10.1016/j.jid.2019.02.006

39. Sugiyama Y, Ota Y, Hara M, Inoue S. Osmotic Stress Up-Regulates Aquaporin-3 Gene Expression in Cultured Human Keratinocytes. Biochim Biophys Acta (2001) 1522(2):82-8. doi: 10.1016/s0167-4781(01)00320-7

40. Pitol AK, Kohn T, Julian TR. Retention of E. Coli and Water on the Skin After Liquid Contact. PloS One (2020) 15(9):e0238998. doi: 10.1371/ journal.pone.0238998

41. Pastar I, O’Neill K, Padula L, Head CR, Burgess JL, Chen V, et al. Staphylococcus epidermidis Boosts Innate Immune Response by Activation of Gamma Delta T Cells and Induction of Perforin-2 in Human Skin. Front Immunol (2020) 11:550946. doi: 10.3389/fimmu.2020.550946

42. Walter S, Rademacher F, Kobinger N, Simanski M, Gläser R, Harder J. RNase 7 Participates in Cutaneous Innate Control of Corynebacterium amycolatum. Sci Rep (2017) 7(1):13862. doi: 10.1038/s41598-017-14383-Z

43. Wang B. Human Skin Rnases Offer Dual Protection Against Invading Bacteria. Front Microbiol (2017) 8:624. doi: 10.3389/fmicb.2017.00624

44. Wanke I, Steffen H, Christ C, Krismer B, Götz F, Peschel A, et al. Skin Commensals Amplify the Innate Immune Response to Pathogens by Activation of Distinct Signaling Pathways. J Invest Dermatol (2011) 131 (2):382-90. doi: 10.1038/jid.2010.328

45. Belkaid Y, Segre JA. Dialogue Between Skin Microbiota and Immunity. Science (2014) 346(6212):954-9. doi: 10.1126/science.1260144

46. Kobayashi T, Voisin B, Kennedy EA, Jo JH, Shih HY, Truong A, et al. Homeostatic Control of Sebaceous Glands by Innate Lymphoid Cells Regulates Commensal Bacteria Equilibrium. Cell (2019) 176(5):982997.e16. doi: 10.1016/j.cell.2018.12.031 
47. Parlet CP, Brown MM, Horswill AR. Commensal Staphylococci Influence Staphylococcus aureus Skin Colonization and Disease. Trends Microbiol (2019) 27(6):497-507. doi: 10.1016/j.tim.2019.01.008

48. Simanski M, Gläser R, Köten B, Meyer-Hoffert U, Wanner S, Weidenmaier C, et al. Staphylococcus aureus Subverts Cutaneous Defense by DAlanylation of Teichoic Acids. Exp Dermatol (2013) 22(4):294-6. doi: $10.1111 /$ exd.12114

49. Torres Salazar BO, Heilbronner S, Peschel A, Krismer B. Secondary Metabolites Governing Microbiome Interaction of Staphylococcal Pathogens and Commensals. Microb Physiol (2021) 31:198-216. doi: $10.1159 / 000517082$

50. Baquero F, Lanza VF, Baquero MR, del Campo R, Bravo-Vázquez DA. Microcins in Enterobacteriaceae: Peptide Antimicrobials in the Eco-Active Intestinal Chemosphere. Front Microbiol (2019) 10:2261. doi: 10.3389/ fmicb.2019.02261

51. Nakatsuji T, Chen TH, Narala S, Chun KA, Two AM, Yun T, et al. Antimicrobials From Human Skin Commensal Bacteria Protect Against Staphylococcus aureus and Are Deficient in Atopic Dermatitis. Sci Transl Med (2017) 9(378):eaah4680. doi: 10.1126/scitranslmed.aah4680

52. Naik S, Bouladoux N, Wilhelm C, Molloy MJ, Salcedo R, Kastenmuller W, et al. Compartmentalized Control of Skin Immunity by Resident Commensals. Science (2012) 337(6098):1115-9. doi: 10.1126/science. 1225152

53. del Campo R, Martínez-García L, Sánchez-Díaz AM, Baquero F. Biology of Hand-to-Hand Bacterial Transmission. Microbiol Spectr (2019) 7(1):205-13. doi: 10.1128/microbiolspec.MTBP-0011-2016

54. Hannigan GD, Grice EA. Microbial Ecology of the Skin in the Era of Metagenomics and Molecular Microbiology. Cold Spring Harb Perspect Med (2013) 3(12):a015362. doi: 10.1101/cshperspect.a015362

55. Oh J, Freeman AF, Park M, Sokolic R, Candotti F, Holland SM, et al. The Altered Landscape of the Human Skin Microbiome in Patients With Primary Immunodeficiencies. Genome Res (2013) 23:2103-14. doi: $10.1101 /$ gr.159467.113

56. Mempel M, Schmidt T, Weidinger S, Schnopp C, Ring J, Abeck D, et al. Role of Staphylococcus aureus Surface-Associated Proteins in the Attachment to Cultured HaCaT Keratinocytes in a New Adhesion Assay. J Invest Dermatol (1998) 111:452-6. doi: 10.1046/j.1523-1747.1998.00293.x

57. Hook M, Foster TJ. Editorial: Cell Surface Proteins of Gram-Positive Pathogenic Bacteria. Front Microbiol (2021) 12:681880. doi: 10.3389/ fmicb.2021.681880

58. Foster TJ. The MSCRAMM Family of Cell-Wall-Anchored Surface Proteins of Gram-Positive Cocci. Trends Microbiol (2019) 27:927-41. doi: 10.1016/ j.tim.2019.06.007

59. Keane FM, Loughman A, Valtulina V, Brennan M, Speziale P, Foster TJ. Fibrinogen and Elastin Bind to the Same Region Within the A Domain of Fibronectin Binding Protein A, an MSCRAMM of Staphylococcus aureus. Mol Microbiol (2007) 63:711-23. doi: 10.1111/j.1365-2958.2006.05552.x

60. Foster TJ. Surface Proteins of Staphylococcus aureus. Microbiol Spect (2019) 7(4). doi: 10.1128/microbiolspec.GPP3-0046-2018

61. Foster TJ. Surface Proteins of Staphylococcus epidermidis. Front Microbiol (2020) 11:1829. doi: 10.3389/fmicb.2020.01829

62. Trivedi S, Uhlemann AC, Herman-Bausier P, Sullivan SB, Sowash MG, Flores EY, et al. The Surface Protein SdrF Mediates Staphylococcus epidermidis Adherence to Keratin. J Infect Dis (2017) 215:1846-54. doi: 10.1093/infdis/jix213

63. Büttner H, Mack D, Rohde H. Structural Basis of Staphylococcus epidermidis Biofilm Formation: Mechanisms and Molecular Interactions. Front Cell Infect Microbiol (2015) 5:14. doi: 10.3389/fcimb.2015.00014

64. Aly R, Levit S. Adherence of Staphylococcus aureus to Squamous Epithelium: Role of Fibronectin and Teichoic Acid. Rev Infect Dis (1987) 9 Suppl 4:S341350. doi: 10.1093/clinids/9.Supplement_4.S341

65. Heilbronner S, Foster TJ. Staphylococcus lugdunensis: A Skin Commensal With Invasive Pathogenic Potential. Clin Microbiol Rev (2020) 34(2): e00205-20. doi: 10.1128/CMR.00205-20

66. Hussain M, Kohler C, Becker K. Role of SrtA in Pathogenicity of Staphylococcus lugdunensis. Microorganisms (2020) 8(12):1975. doi: 10.3390/microorganisms8121975
67. Grange PA, Raingeaud J, Morelle W, Marcelin AG, Calvez V, Dupin N. Characterization of a Propionibacterium acnes Surface Protein as a Fibrinogen-Binding Protein. Sci Rep (2017) 7:1-14. doi: 10.1038/s41598017-06940-3

68. Baquero F, Coque TM, Galán JC, Martinez JL. The Origin of Niches and Species in the Bacterial World. Front Microbiol (2021) 12:657986. doi: 10.3389/fmicb.2021.657986

69. Nerandzic MM, Donskey CJ. Sensitizing Clostridium difficile Spores With Germinants on Skin and Environmental Surfaces Represents a New Strategy for Reducing Spores via Ambient Mechanisms. Pathog Immun (2017) 2 (3):404-21. doi: 10.20411/pai.v2i3.221

70. Reigadas E, Vázquez-Cuesta S, Villar-Gómara L, Onori R, Alcalá L, Marín $\mathrm{M}$, et al. Role of Clostridioides difficile in Hospital Environment and Healthcare Workers. Anaerobe (2020) 63:1022049. doi: 10.1016/j.anaerobe. 2020.102204

71. O'Mahony R, Basset C, Holton J, Vaira D, Roitt I. Comparison of Image Analysis Software Packages in the Assessment of Adhesion of Microorganisms to Mucosal Epithelium Using Confocal Laser Scanning Microscopy. J Microbiol Methods (2005) 61(1):105-26. doi: 10.1016/ j.mimet.2004.11.020

72. Casewell M, Phillips I. Hands as Route of Transmission for Klebsiella Species. Br Med J (1977) 2(6098):1315-7. doi: 10.1136/bmj.2.6098.1315

73. Aracil-Gisbert S, Guerra-Pinto N, Pérez-Cobas AE, Fernández-de-Bobadilla MD, Ortiz-Fernández A, Cruz Soriano-Cuesta C, et al. Influence of the "Built Environment" in the Epidemiology of Antibiotic Resistance in High-Risk Nosocomial Areas. In: 31st European Congress of Clinical Microbiology and Infectious Diseases. Communication (2021). p. 4370.

74. Hanis CL, Garrett KE, Essigmann HT, Robinson DA, Gunter SM, Nyitray AG, et al. Household Aggregation of Staphylococcus aureus by Clonal Complex and Methicillin Resistance Profiles in Starr County, Texas. Eur J Clin Microbiol Infect Dis (2017) 36(10):1787-93. doi: 10.1007/s10096-0172992-x

75. Valverde A, Grill F, Coque TM, Pintado V, Baquero F, Cantón R, et al. High Rate of Intestinal Colonization With Extended-Spectrum-Beta-LactamaseProducing Organisms in Household Contacts of Infected Community Patients. J Clin Microbiol (2008) 46(8):2796-9. doi: 10.1128/JCM.01008-08

76. Valverde A, Turrientes MC, Norman F, San Martín E, Moreno L, PérezMolina JA, et al. CTX-M-15-Non-ST131 Escherichia coli Isolates are Mainly Responsible of Faecal Carriage With ESBL-Producing Enterobacteriaceae in Travellers, Immigrants and Those Visiting Friends and Relatives. Clin Microbiol Infect (2015) 21(3):252.e1-4. doi: 10.1016/j.cmi.2014.09.021

77. Loudon I. Semmelweis and His Thesis. J R Soc Med (2005) 98(12):555. doi: $10.1258 /$ jrsm.98.12.555

78. Kjølen H, Andersen BM. Handwashing and Disinfection of Heavily Contaminated Hands-Effective or Ineffective? J Hosp Infect (1992) 21 (1):61-71. doi: 10.1016/0195-6701(92)90154-e

79. Nystrom B. Impact of Handwashing on Mortality in Intensive Care: Examination of the Evidence. Infect Control Hosp Epidemiol (1994) 15 (7):435-6. doi: 10.1086/646947

80. Vandegrift R, Bateman AC, Siemens KN, Nguyen M, Wilson HE, Green JL, et al. Cleanliness in Context: Reconciling Hygiene With a Modern Microbial Perspective. Microbiome (2017) 5(1):76. doi: 10.1186/s40168-017-0294-2

81. del Campo R, Sánchez-Díaz AM, Zamora J, Torres C, Cintas LM, Franco E, et al. Individual Variability in Finger-to-Finger Transmission Efficiency of Enterococcus faecium Clones. Microbiologyopen (2014) 3(1):128-32. doi: $10.1002 / \mathrm{mbo3} .156$

82. Lingaas E, Fagernes M. Development of a Method to Measure Bacterial Transfer From Hands. J Hosp Infect (2009) 72(1):43-9. doi: 10.1016/ j.jhin.2009.01.022

83. Hübner NO, Hübner C, Kramer A, Assadian O. Survival of Bacterial Pathogens on Paper and Bacterial Retrieval From Paper to Hands: Preliminary Results. Am J Nurs (2011) 111(12):30-4. doi: 10.1097/ 01.NAJ.0000408181.37017.82

84. King MF, López-García M, Atedoghu KP, Zhang N, Wilson AM, Weterings $M$, et al. Bacterial Transfer to Fingertips During Sequential Surface Contacts With and Without Gloves. Indoor Air (2020) 30(5):993-1004. doi: 10.1111/ ina. 12682 
85. Cosseau C, Romano-Bertrand S, Duplan H, Lucas O, Ingrassia I, Pigasse C, et al. Proteobacteria From the Human Skin Microbiota: Species-Level Diversity and Hypotheses. One Health (2016) 2:33-41. doi: 10.1016/j.onehlt.2016.02.002

86. Lee M, Jung Y, Kim E, Lee HK. Comparison of Skin Properties in Individuals Living in Cities at Two Different Altitudes: An Investigation of the Environmental Effect on Skin. J Cosmet Dermatol (2017) 16(1):26-34. doi: $10.1111 /$ jocd. 12270

87. Boutin S, Sauvage C, Bernatchez L, Audet C, Derome N. Inter Individual Variations of the Fish Skin Microbiota: Host Genetics Basis of Mutualism? PloS One (2014) 9(7):e102649. doi: 10.1371/journal.pone.0102649

88. Apprill A, Miller CA, Van Cise AM, U'Ren JM, Leslie MS, Weber L, et al. Marine Mammal Skin Microbiotas are Influenced by Host Phylogeny. R Soc Open Sci (2020) 7(5):192046. doi: 10.1098/rsos.192046

89. Rupec RA, Boneberger S, Ruzicka T. What is Really in Control of Skin Immunity: Lymphocytes, Dendritic Cells, or Keratinocytes? Facts and Controversies. Clin Dermatol (2010) 28(1):62-6. doi: 10.1016/j.clindermatol.2009.04.004

90. Leung MH, Wilkins D, Lee PK. Insights Into the Panmicrobiome: Skin Microbial Communities of Chinese Individuals Differ From Other Racial Groups. Sci Rep (2015) 5:11845. doi: 10.1038/srep11845

91. Trushin MV. The Possible Role of Electromagnetic Fields in Bacterial Communication. J Microbiol Immunol Infect (2003) 36(3):153-60.

92. Norris V, Hyland GJ. Do Bacteria Sing? Sonic Intercellular Communication Between Bacteria may Reflect Electromagnetic Intracellular Communication Involving Coherent Collective Vibrational Modes That Could Integrate Enzyme Activities and Gene Expression. Mol Microbiol (1997) 24(4):87980. doi: 10.1046/j.1365-2958.1997.3951756.x

93. Vakis AI, Yastrebov VA, Scheibert J, Nicola L, Dini D, Minfray C, et al. Modeling and Simulation in Tribology Across Scales: An Overview. Tribol Int (2018) 125:169-99. doi: 10.1016/j.triboint.2018.02.005

94. Ennos R, Warman P. The Frictional Properties of Human Finger Pads. Compar Biochem Physiol Part A (2009) 2(153):S123-4. doi: 10.1016/ j.cbpa.2009.04.204

95. Kelliher TP, Rittscher J, Tu P. Composition of Latent Fingerprints - Friction Skin. In: Encyclopedia of Forensic and Legal Medicine. Oxford: Elsevier (2005). p. 1-7.

96. Yum SM, Baek IK, Hong D, Kim J, Jung K, Kim S, et al. Fingerprint Ridges Allow Primates to Regulate Grip. Proc Natl Acad Sci USA (2020) 117:3166573. doi: $10.1073 /$ pnas. 2001055117
97. Pasumarty SM, Johnson SA, Watson SA, Adams MJ. Friction of the Human Finger Pad: Influence of Moisture, Occlusion and Velocity. Tribol Lett (2011) 44(2):117-37. doi: 10.1007/s11249-011-9828-0

98. Mabuchi K, Sakai R, Yoshida K, Ujihira M. Effect of Ageing on Friction of Human Fingers. Biosurf Biotribol (2018) 4(4):117-21. doi: 10.1049/ bsbt.2018.0030

99. Liu X, Gad D, Lu Z, Lewis R, Carré MJ, Matcher SJ. The Contributions of Skin Structural Properties to the Friction of Human Finger-Pads. Proc Inst Mech Eng Part J: J Eng Tribol (2015) 229(3):294-311. doi: 10.1177/ 1350650114567699

100. Derler S, Gerhardt LC. Tribology of Skin: Review and Analysis of Experimental Results for the Friction Coefficient of Human Skin. Tribol Lett (2012) 45(1):1-27. doi: 10.1007/s11249-011-9854-y

101. Veijgen NK, Masen MA, van der Heide E. Variables Influencing the Frictional Behaviour of In Vivo Human Skin. J Mech Behav BioMed Mater (2013) 28:448-61. doi: 10.1016/j.jmbbm.2013.02.009

102. Veijgen NK, van der Heide E, Masen MA. A Multivariable Model for Predicting the Frictional Behaviour and Hydration of the Human Skin. Skin Res Technol (2013) 19(3):330-8. doi: 10.1111/srt.12053

Conflict of Interest: The authors declare that the research was conducted in the absence of any commercial or financial relationships that could be construed as a potential conflict of interest.

Publisher's Note: All claims expressed in this article are solely those of the authors and do not necessarily represent those of their affiliated organizations, or those of the publisher, the editors and the reviewers. Any product that may be evaluated in this article, or claim that may be made by its manufacturer, is not guaranteed or endorsed by the publisher.

Copyright (c) 2021 Baquero, Saralegui, Marcos-Mencía, Ballestero, Vañó-Galván, Moreno-Arrones and del Campo. This is an open-access article distributed under the terms of the Creative Commons Attribution License (CC BY). The use, distribution or reproduction in other forums is permitted, provided the original author(s) and the copyright owner(s) are credited and that the original publication in this journal is cited, in accordance with accepted academic practice. No use, distribution or reproduction is permitted which does not comply with these terms. 